\title{
A Study on The Relation of Three Knife Marks and Silkworm Lines in Chinese Buddhism Statues
}

\author{
Jiahua Jiang ${ }^{1, a}$ \\ ${ }^{1}$ Shenzhen Polytechnic. Xili Town, NanShan District, Shenzhen, P.R.China. \\ ajjh@szpt.edu.cn
}

\begin{abstract}
The Three Knife Marks of Chinese Buddhism statues came from a sacred event of statues in Chinese Southern and Northern Dynasties period, which told us that Guanyin undertook the sufferings for human, thus left three wounds, so called the Three Knife Marks. This paper holds that the sacred marks actually refer to the Buddha's three neck lines in shape, which is called silkworm lines of the neck. Many statues created in northern and Southern Dynasties were imitated from the format of the western regions. According to the Archaeological records, some of these statues have possessed neck lines, especially the statue of the Bodhisattva, with one, two or three neck lines. And most common statues are characterized by the three lines pattern. According to the author's research, there has been an important correlation between the Three Knife Marks and silkworm lines. This hypothesis, the author believes, resulted from the sacred narration of the silkworm lines by the Buddhist.
\end{abstract}

Keywords: Statues; Three Knife Marks; Neck Line; Silkworm Lines

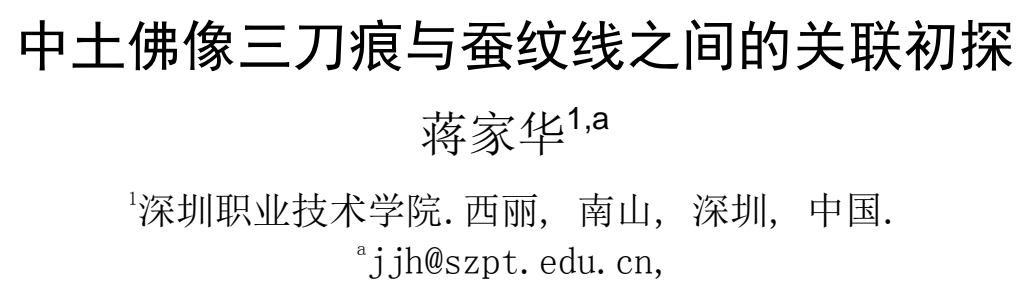

中文摘要. 中土佛教造像中的 “三刀痕”， 来源于中国南北朝时期的一次佛像显圣事 件, 说是观音佛像代人受难而留下的三道刀 痕，顾名思义称为 “三刀痕”。笔者认为, 被神圣化的 “三刀痕” 印迹, 实际上是指佛 像塑造中的三道颈纹线, 即通常所说的颈部 蚕纹线。南北朝时期佛像塑造的范式大多还 是以西域传来的佛像为塑造的模仿对象。根 据实物考古资料, 这些佛像部分已经带有颈
纹线, 特别是菩萨塑像, 并从一道至三道不 等, 更常见的是以三道纹为特征。因此, 通 过笔者研究发现, 佛像的 “三刀痕” 与蚕纹 线存在关联, 这种猜想, 很可能是宗教徒借 用佛像的羊纹线进行神圣化叙事而导致的 结果。

关键词：佛像; 三刀痕; 颈纹线; 蚛纹线 


\section{1. 引言}

有唐一代，审美趋向于人物体态丰满， 颈纹的塑造有明显的凹凸特征, 呈现出所谓 的蚕纹线, 与过去 (南北朝) 比较浅平的颈 纹形成强烈对比。宋明以降, 唐朝的饱满的 颈项蚕纹又渐趋偏平, 这是与宋、明时代审 美倾向崇尚相对清瘦的趣味相关。但是在菩 萨造像中颈项蚕纹线的特征的传承依然比 较明显 (分地区而论)。需要特别指出的是, 颈纹线的塑造，在印度胖陀罗贵霜王朝时 期, 已经有了比较健美的颈纹线塑造, 甚至 部分带有蚕纹特征。因此, 中土的佛像颈纹 线的塑造着实是受外来影响而形成。唐宋以 降, 颈纹线的塑造基本已经中土化, 以中土 人物为现实参考对象。本文将从”三刀痕” 显圣故事为契, 以小见大, 对中土的佛像颈 纹线到隋唐时期的流变作一梳理。本文即将 从 “三刀痕” 的来历、三刀痕与虫纹线的关 联、蚕纹线到两宋以降时期的流变等方面进 行讨论。

\section{2. 佛像 “三刀痕” 的来历}

佛像”三刀痕” 在历代佛教典籍中多处 记载, 其中大部分都集中在一个神异故事 中。比较完整的记载出现在唐代道宣《集神 州三宝感通录》中: “元魏天平中, 定州募 士孙敬德, 防于北陲, 造观音金像, 年满将 还, 常加礼事。后为劫贼横引, 禁于京狱。 不胜拷掠, 遂妄承罪, 并断死刑, 明旦行决。 其夜礼拜、忓悔, 泪下如雨。启曰: ‘今身 被枉, 当是过去枉他。愿偿债, 毕誓不重作。' 又发大愿云云。言已, 少时, 依俙如梦, 见 一沙门教诵《观世音救生经》, 经有佛名, 令诵千遍, 得度苦难。敬德炊觉起坐, 缘之 了无参错。比至平明, 已满一百遍, 有司执 缚向市, 且行且诵。临欲加刑, 诵满千遍, 执刀下斫, 折为三段, 不损皮肉。易刀又斫, 凡经三换刀, 折如初。监当官人莫不惊异, 具状奏闻。丞相高欢表请其事，遂得免死， 勅写此经传之。今所谓《高王观世音 (经)》 是也。敬德放还, 设斋报愿。出, 在防像乃 见项上有三刀痕。乡亲同酰, 叹其通感。见 《齐志》及《権异》等记。”[1]

从文献上看, 道宣是抄录《齐志》与《旅
异》中的记载。再看看其他文献对类似事件 的记载: “吴郡人沈英, 被系处死。临刑市 中日, 诵观世音名号, 心口不息, 刀刃自断, 因而被放。一云, 吴人陆晖, 系狱分死。乃 令家人造观世音像, 冀得免死。临刑三刀, 其刀皆折。官问之。故答云: ‘恐是观世音 慈力。' 及看像项上, 乃有三刀痕见。因奏, 获免。出《宣验记》。”[2]

《宣验记》出自南朝刘宋的刘义庆著作, 可知这时期的一些观音造像的颈项造型带 有明显的三道颈纹线, 而大多佛像基本上没 有颈纹。因此, 出现颈纹的佛像为神圣性的 造作创造了契机。一些神圣叙事为了增强佛 像显圣的逼真, 甚至还在”三刀痕” 印迹处 制造流血的迹象, 并不再限于观音菩萨。如 《地藏菩萨像灵验记》记载: “抚州刺史祖 氏，信心真固...... 造金色地藏一躯。长三 尺, 通光立像, 尽礼供思..... 后父行抚州, 路中遇怨家，（怨家）即拔利刃斩之。有一 沙门, 其身金色, 以手拒刃, 以头受刃, 被 刑害卧地。怨家谓巳杀, 散去。父谓希奇, 自免刑害。到祖氏家, 具证前事, 生希有心, 共往像所礼拜之。见像头有三刀痕, 金色少 变, 似血流。既知地藏菩萨, 代受刃, 救父 母难。其父发信, 祖迎其母, 三人在抚州而 住，昼夜礼供。”[3]

这则灵验显圣故事同样在菩萨头（颈） 处出现三刀痕。所不同的是, 是地藏菩萨而 不是观音菩萨代人受刃。这就为佛教塑像” 三刀痕”颈纹印迹的神圣性赋予了普遍性的 可能。即，凡是有三道颈纹线的佛教塑像都 具有神圣的灵验。佛教塑像作为宗教圣物, 神圣的化身, 其塑像的每一个组成部分无不 被宗教徒赋予其神圣性, 以期获得僧俗的膜 拜, 增强影响, 吸引更多的信徒信仰。为了 获得僧俗的尊崇, 通过制造显圣, 使民众对 佛教的信仰更加坚定不疑。米尔恰. 伊利亚 德认为, 每一个空间都意味着一个显圣物, 都意味着神圣空间的切入, 这种神圣的切入 把一处土地从其周围的宇宙空间分离出来, 并使得它们有了品质上的不同。[4]也就是 说, 佛像需要显圣, 需要与普通的世俗物分 离出来, 这是佛像颈纹” 三刀痕” 显圣的宗 教神圣意义所在。实际上, 佛像” 三刀痕” 显圣故事及其演化至南北朝以降, 已经普遍 
佛像造作产生了直接影响。[7] 因此, 对新 疆克孜尔石窟壁画 (雕塑已不存) 佛像颈纹

\section{3. 佛像 “三刀痕” 与䖯纹线}

站在世俗的立场, ”三刀痕” 的显圣事 件只是教徒为了宣扬宗教信仰、吸引信众的 一种方式。通过研究发现, ”三刀痕” 的呈 现笔者认为只是佛像塑造中的颈纹线而已, 从一条至三条不等, 而很多佛像根本就没有 颈纹线。魏晋时期, 佛像多从西域传来, 有 些直接来自印度本土。因此, 为了追溯中土 佛像颈纹线塑造的参照, 需要考察1-6世纪 西域以及部分印度佛像颈纹线塑造的特征, 而这一时期, 中土正是受到这些佛像塑造风 格的影响。

在考察中土佛像颈纹线塑造之前, 先考 察对中土有直接影响的西域佛像的颈纹线 造型特点。笔者选择新疆拜城的克孜尔石窟 作为考察对象。这是因为, 今新疆拜城, 为 古代龟兹之地, 龟兹是西域诸城邦中较大的 的一个, 地处古代东西方交通的枢纽。佛教 作为龟兹的国教, 非常发达。在《出三藏記 集》卷11中有关于龟兹佛教的记载: “拘夷 (龟兹) 国寺甚多, 修饰至丽。王宫雕镂, 立佛形像, 与寺无异。有寺名达慕蓝 (百七 十僧), 北山寺名致隶蓝 (五十僧), 剑慕王 新蓝 (六十僧), 温宿王蓝 (七十僧)。右四寺 佛图舌弥所统。寺僧皆三月一易屋床座, 或 易蓝者。未满五腊, 一宿不得无依止。王新 僧伽蓝(九十僧, 有年少沙门, 字鸠摩罗, 才大高, 明大乘学, 与舌弥是师徒, 而舌弥 阿含学者也)。阿丽蓝 (百八十比丘尼), 输 若干蓝 (五十比丘尼), 阿丽跋蓝 (三十尼 道), 右三寺比丘尼统依舌弥受法戒, 比丘 尼外国法不得独立也。此三寺尼, 多是葱岭 以东王侯妇女，为道远集斯寺。”[5]

关于龟兹佛教的发达，在《晋书. 四夷 传》也有记载: “龟兹国西去洛阳八千二百 八十里, 俗有城郭, 其城三重, 中有佛塔千 所..... 王宫壮丽, 焕若神居。”[6] 在霍 旭初、王建林的论文中谈到, 龟兹与于阗是 我国佛教的首及地区。佛教初传内地, 这两 地是重要的媒介...... 开丵石窟是龟兹佛 教艺术的重要形式, 龟兹石窟艺术随着佛教 向东传播, 影响了我国内地石窟的开糋及其 艺术形式。特别是克孜尔石窟, 对中土地域
线造形的考察, 即可找到中土佛像颈纹线的 传承证据。在时间上，主要是对克孜尔石窟 的初创期 (公元三世纪末一四世纪中) 、发 展期 (公元四世纪中一五世纪末) 的壁画资 料进行甄别, 因为这两个时期既是石窟壁画 受印度有直接影响和间接影响的时期, 同时 也是克孜尔石窟影响中土佛教艺术的时期。 克孜尔石窟地处古丝绸之路的中线, 在公元 1-3世纪, 往西, 直接可以接触到曾在敦煌 和祁连山的游牧民族建立的印度贵霜王朝 的佛教艺术, 而这时期正是印度牛陀罗艺术 的活跃期。 [8] 从2-3世纪遗存的健陀罗佛 像, 列举两尊: 《佛陀立像》, 健陀罗呵多 (Swât) 国地区, 公元2-3世纪, 片岩, 73 厘米x32.7厘米, 柏林印度艺术博物馆收藏

（MIK I 217）; 《佛陀显水火神通》，阿 富汗, 公元3世纪, 片岩, 74厘米 x50厘米, 柏林印度艺术博物馆收藏（MIK I 67）。[9] 以上两尊佛像是典型的犍陀罗艺术的体现, 颈项纹明显, 吸收希腊塑像的肌肉健壮、脖 粗的特征。克孜尔石窟壁画之初创期在人物 造型方面, 具有明显的外来风格, 尤其是健 陀罗造形艺术的影响。虽然健陀罗艺术主要 是在雕塑, 但其艺术特征在龟兹壁画上也得 到反映。下面具体分析初创期 (公元三世纪 末一四世纪) 佛像颈纹线的造型特征。在克 孜尔石窟中:

一一八窟, 《伎乐与花鸟》, 一带头光 的伎乐有一道明显的颈纹线。

九二窟, 《菩萨》, 图中菩萨有明显的 两道颈纹线。

七七窟，《金刚神》，图中金刚神有一 道颈纹线。

七七窟, 《天女》, 带头光, 图中天女 有一道颈纹线。

七七窟, 《角道顶部全景》, 带头光, 图中天女均有一道颈纹线。

七七窟, 《伎乐天》等, 带头光, 图中 天女均有一至二道颈纹线不等。

四八窟，《飞天》，图中飞天均有一道 颈纹线不等。[10]

以上是克孜尔初创期壁画造像中颈纹 线的塑造特征。从上面图片资料可以看出, 
造像中的颈纹线基本上大多只有一条, 极少 数有两条。这时期中土正处在西晋

（265-317）时期, 这时佛教造像还没大量 传入中土, 云岗石窟也还没有开丵。下面再 考察克孜尔发展期 (公元四世纪中一五世纪 末, 北魏云岗石窟在这期间开丵。) 的壁画 资料, 会发现在造像的颈纹线特征上, 出现 了很大的变化。整理如下:

三八窟, 《弥勒菩萨说法图局部》、《佛 传图局部》、《天宫伎乐》、《慈力王本生》, 带头光, 图中菩萨有三条颈纹线。

九二窟, 《摩诃萨埵太子本生》, 图中 头像有三条颈纹线。

三八窟，《因缘故事》、《涅槃图》， 带头光、身光, 图中头像有三条颈纹线。八 四窟, 《佛传图》, 图中部分头像有三条颈 纹线。

一七一窟, 《梵摩那比丘》, 图中有明 显的三条颈纹线。[11]

通过上面图例可以看出, 相比克孜尔石 窟初创期的图像颈纹线塑造, 发展期的造像 出现三条颈纹线的现象已经比较多见, 而且 出现较深的蚕纹特征。这个时期, 中土地区 的一些佛教造像已经出现三条颈纹线, 所谓 “三刀痕” , 就不足奇怪了, 体现了这时期 龟兹与中土佛教的频繁交往, 以及中土佛教 造像对西域龟兹等地佛教造像风格的吸收。 因此, 南北朝时期关于佛像”三刀痕” 显圣 的世俗渊源，找到了比较充分的现实依据。

\section{4. 佛像三刀痕颈项纹从南北朝到两宋以后 的演变}

\section{1 颈项纹演变各时期简述}

整个魏晋南北朝时期玄学与佛教宗教 气氛浓厚, 文学和艺术上讲究魏晋风度。在 佛教造像上渐渐有了中土特点, 倾向于比较 瘦弱的艺术风格, 佛像颈纹线的塑造浅平, 缺乏体量感, 没有象蚕纹似的体感。直到唐 代, 开阔包容的大国气象, 丰䑂之风在艺术 领域渐起。在佛像颈纹线的塑造上也表现为 丰舆的蚕纹特征, 并加以夸张。北宋以降, 佛像颈纹线的塑造以又趋向浅平为其特征, 这是与北宋文人社会的兴起、提倡清瘦的社 会风尚相关, 颈项相对细长。而金、元两朝,
则带遗留有西域、唐朝综合的艺术风格, 颈 纹线的塑造体现为健美、健壮的艺术风格。 下面举出一些个例以考察南北朝之后佛像 颈纹线塑造的基本演变。

\section{2 隋代时期颈纹线特征}

隋朝颈纹线呈浅平特征, 例举如下:

《菩萨像》, 彩塑, 甘肃敦煌莫高窟第 244窟北壁佛东侧, 高317厘米, 泥, 粉彩。 塑像有三道浅平的颈纹线。

《释迦牟尼与文殊、普贤菩萨》，石胎 泥塑, 甘肃天水麦积山石窟第13号摩崖, 主 佛高16米, 文殊、普贤高13米, 泥、石。造 像颈部有非常明显的三道颈纹线。颈项短而 健硕，略带西域之风。

《观音菩萨立像》, 圆雕, 发现于陕西 西安一古寺内, 通座高249厘米, 石灰岩, 美国波士顿博物馆藏。观音头像三道颈纹线 明显, 整个塑像已经摆脱西域造型影响, 呈 现中土塑像风格。[12]

\section{3 唐代时期颈纹线特征}

唐朝颈纹线特征, 是由初唐的浅平向盛 唐丰舆的虫纹线过渡，例举如下:

《菩萨》, 彩塑, 初唐, 甘肃莫高窟第 205窟佛坛上南侧, 高204厘米, 泥, 粉彩。 三道颈纹线浅平。《大卢舍那佛》, 半圆雕, 唐, 河南洛阳龙门石窟奉先寺西壁中央, 通 高1714厘米, 头高400厘米, 耳长190厘米, 石质。颈纹线比较浅平, 受印度牛陀罗风格 影响明显。

《虚空菩萨坐像》, 圆雕, 盛唐, 陕西 西安安国寺遗址出土, 通座高78厘米, 白大 理石, 陕西省博物馆藏。菩萨像颈项纹呈现 丰钱的蚕纹线, 是盛唐的典型塑造。《摩崖 石雕》, 唐, 四川乐山凌云山, 通高71米, 石质。三条颈项线突出, 具有虫纹特征。《胁 侍菩萨》, 唐, 甘肃永靖炳灵寺石窟第 64 龛, 高 101 厘米, 石质。菩萨颈项有三道高 高凸起的蚕纹线。 [13]

\section{4 两宋、辽时期颈纹线特征}

北宋、南宋, 颈纹线塑造由北宋自然、 优美的蚕纹，向北宋后期较扁平的颈纹线过 渡, 兹各举两例: 
《观音菩萨坐像》, 北宋, 浙江金华万 佛塔塔基出土, 高49.8厘米, 铜、金, 中国 历史博物馆藏。观音造像完全中土化, 颈部 有三道优美自然的蚕纹。部分保留了盛唐时 期的遗风。

《观音菩萨乘麟像》, 彩塑, 北宋, 山 西长子崇庆寺三大士殿, 通高257厘米, 泥、 粉彩。观音颈纹线塑造有三道比较浅近的蚕 纹, 微微凸起。《观音菩萨坐像》, 宋, 高 118厘米, 木质。美国纽约大都会博物馆藏。 观音三道颈项纹趋向扁平, 略呈带状, 但较 南北朝时期健硕。应该是出于北宋后期塑 像。《紫竹观音》, 南宋, 四川安岳塔子山 毗卢洞, 高280厘米, 石, 粉彩。观音三道 颈项纹趋向扁平，略呈扁带状。[14]

由此可见, 两宋时期的颈纹线塑造受到 了这一时期理学的影响, 简约、简淡的审美 风格反映在了佛像的塑造中。鉴于篇幅关 系, 在上面的例举中, 本文仅例举了观音菩 萨塑像, 没有涉及到佛陀类、罗汉类、护法 神类塑像的颈纹线特征, 特此说明。

此外, 山西大同华严寺中塑造的数尊辽 代 (907-1125) 菩萨立项的颈项纹基本不加 塑造, 只是刻上三道凹线, 仅体现一种扁平 的装饰特征。金、元、时期的颈项纹又略带 蚕纹凸起, 这种审美的变化, 体现了各个民 族审美趋向的复杂心理。至于金、元、明清 时期的复杂性, 鉴于篇幅关系这里不再敖 述。

\section{5. 结束语}

中土佛像” 三刀痕” 的显圣, 是佛教教 内的一种神圣叙事, 佛像 “三刀痕” 反映到 具体的佛像塑造, 只不过是三道颈项纹而 已。颈项纹的出现, 可以追溯到印度峍陀罗 佛教造像的艺术时期。通过考察考察新疆克 孜尔石窟壁画关于颈项纹塑造的特征, 以及 在隋唐以后风格的大致演变, 可以比较明显 的觉察到颈纹线演变的痕迹。对于蚕纹线而 言, 更多的是指唐朝时期丰满的颈纹线所体 现的特征。从佛教造像艺术角度来说, 颈项 纹可能是个很小的角度, 但是可以一管窥 豹, 抛砖引玉, 以作出更多关于佛教艺术方 面细微角度的考察与研究, 这是本文研究的 意义所在。

\section{致谢}

该文为国家社科基金重大项目“多卷本 《中国寺观文化史》”(项目编号: 13\&ZD079) 的阶段性成果。并对该项目团队对本文的建 议和支持表示诚挚的感谢。

\section{References}

[1] Shi Daoxuan, Chinese Buddhist Communication Set, CBETA, T52, no. 2106, pp.420.

[2] Shi Falin, Differentiation Theory, CBETA, T52, no. 2106, pp.539.

[3] Shi Changjin, Ksitigarbha Bodhisattva miraculous stories, CBETA, X87, no. 1638, pp.588.

[4] Mircea Eliade, Das Heilige und das Profane, Insel Verlag GmbH, pp.5, 1998.

[5] Seng You, Chu Sanzang Set, CBETA, T11, no. 2106, pp.79.

[6] Fang Xuanling, Jin Books, vol.97, Zhonghua Press, pp.2543, 1974.

[7] Duan Wenjie, Chinese Murals Sets, vol.8, pp.1-2, 1992.

[8] Lin Ran, On the Gandhara Buddhism Statues Art, Xinjiang Arts, vol.5, 1996.

[9] Helmut Uhlig, Das Bild Des Buddha, Social Science Press, pp.94-108, 2010.

[10]Duan Wenjie, Chinese Murals Sets, vol.8, pp.8-41, 1992.

[11]Duan Wenjie, Chinese Murals Sets,vol.8, pp.44-181, 1992.,

[12]Lang Shaojun, Liu Shuji \& Zhou Maosheng, Chinese art dictionary, pp.85-89, 1996.

[13]Lang Shaojun,Liu Shuji \& Zhou Maosheng, Chinese art dictionary, pp.93-124, 1996.

[14]Lang Shaojun, Liu Shuji \& Zhou Maosheng, Chinese art dictionary, pp.135-161, 1996. 